Chapman University

Chapman University Digital Commons

Mathematics, Physics, and Computer Science Science and Technology Faculty Articles and

Faculty Articles and Research

Research

2-17-2021

Investigating the Lagged Relationship between Smap Soil

Moisture and Live Fuel Moisture in California, USA

Shenyue Jia

Seung Hee Kim

Son V. Nghiem

Keun Hang S. Yang

Menas Kafatos

Follow this and additional works at: https://digitalcommons.chapman.edu/scs_articles

Part of the Environmental Indicators and Impact Assessment Commons, Environmental Monitoring Commons, and the Soil Science Commons 


\section{Investigating the Lagged Relationship between Smap Soil Moisture and Live Fuel Moisture in California, USA}

\section{Comments}

This is a pre-copy-editing, author-produced PDF of a paper presented at IGARSS 2020 - 2020 IEEE

International Geoscience and Remote Sensing Symposium in September-October 2020. The definitive publisher-authenticated version is available online at https://doi.org/10.1109/

IGARSS39084.2020.9324676.

\section{Copyright}

(C) 2021 IEEE. Personal use of this material is permitted. Permission from IEEE must be obtained for all other uses, in any current or future media, including reprinting/republishing this material for advertising or promotional purposes, creating new collective works, for resale or redistribution to servers or lists, or reuse of any copyrighted component of this work in other works. 


\title{
INVESTIGATING THE LAGGED RELATIONSHIP BETWEEN SMAP SOIL MOISTURE AND LIVE FUEL MOISTURE IN CALIFORNIA, USA
}

\author{
Shenyue Jial ${ }^{1}$ Seung Hee Kim ${ }^{1}$, Son V. Nghiem², Keun Hang S. Yang ${ }^{1}$, Menas Kafatos ${ }^{1}$ \\ ${ }^{1}$ Center of Excellence in Earth System Modeling and Observations (CEESMO), Chapman University, \\ Orange, CA USA \\ ${ }^{2}$ Jet Propulsion Laboratory, California Institute of Technology, Pasadena, CA, USA
}

\begin{abstract}
Live fuel moisture (LFM), defined as the ratio between water in the fresh biomass out of the dry biomass, is a vital measurement of vegetation water content and flammability. In this study, we investigated the dynamics of in-situ measurement of LFM at all the active sites in California, USA and revealed the difference between evergreen forest and shrub/scrub, the two dominant land cover types in California's fire-prone regions. We found that LFM of evergreen forest responses to soil moisture increase later than shrub/scrub, due to a later occurrence of major precipitation, a lower air temperature, and the different plant physiology. The comparison between SMAP L-band radiometer soil moisture and LFM showed that the lag between the rise in soil moisture and the response from LFM was much longer in evergreen forest. Compared with the evergreen forest, LFM of shrub/scrub was more sensitive to the inter-annual variability of soil moisture due to plant physiology and air temperature.
\end{abstract}

Index Terms - Live fuel moisture, SMAP, soil moisture, wildfire, California

\section{INTRODUCTION}

Measuring the amount of moisture content contained in plants, live fuel moisture (LFM) is a critical variable in assessing fire danger and fire behavior. LFM is closely related to fire ignition, propagation, and intensity $[1,2]$ and is a key parameter in projecting fire danger. Although LFM has been measured across the world, especially in the Mediterranean-climate ecosystems, U.S. maintains the world's largest LFM database, with in-situ LFM measurements taken at more than 3000 sites across the fireprone regions of the entire country. Earlier studies focused on developing empirical models to estimate LFM using optical and other remote sensing data [3-6]. Geographical extent of these studies is often constrained to a small region, with a relatively homogeneous land cover type and involving less than 30 LFM sites. Recently, efforts have been made to use radiative transfer models $[7,8]$ and machine learning methods [9] to develop regional and global products of LFM upon various types of land cover using a broad source of optical and microwave remote sensing imageries. Yet investigation on the LFM change at regional level to facilitate LFM modeling and estimation is still limited. Study is much needed to reveal and understand land cover difference, interannual variability, and the strength of seasonality for LFM dynamics in different land cover types.

As an indicator of vegetation health, LFM responses to the input of moisture over the surface and root zone soil with a lag, as the soil moisture (SM) is vital for plant growth and needs time to be assimilated into plant biomass. This lagged relationship enables a new method of LFM modeling and outlook calculation with remotely sensed soil moisture data [6]. The length of the lag depends highly on a few water balance metrics and the plant physiology. In this study, we aim to investigate the LFM dynamics in California, state with the highest number of LFM sites in the U.S. We utilized all the active LFM sites in California to reveal the change of LFM in various land cover types. Furthermore, we compared the LFM with SM available from NASA Soil Moisture Active Passive (SMAP) products to examine the difference in the lag between SM change and the responding change in LFM across different land cover types. This work will advance the understanding on the relationship between SM and vegetation water content and help improving the modeling of LFM.

\section{DATA AND METHOD}

In this study, we collected LFM measurements in California since March $1^{\text {st }}$, 2015 from the National Fuel Moisture Database. Currently, there are 224 active LFM sites collecting measurements in California, covering a broad spectrum of land cover types, including evergreen forest, shrub/scrub, herbaceous, deciduous forest, mixed forest, and open land (Fig. 1). LFM is measured by clipping live foliage, weighing when fresh $\left(W_{w}\right)$, re-weighing after oven-dried $\left(W_{d}\right)$, then applying following equation:

$$
\left.L F M=\frac{W_{w}-W_{d}}{W_{d}} \times 100 \% \text { (Eq. } 1\right) .
$$

LFM is measured mostly on a biweekly basis by local fire department and reported to the National Fuel Moisture Database. Yet a longer interval between measurements can 
be possible due to the limited manpower or other disruption. Fire danger is considered low for LFM greater than $120 \%$, moderate between $80 \%$ and $120 \%$, high between $60 \%$ and $80 \%$, and critical less than $60 \%$ [10].

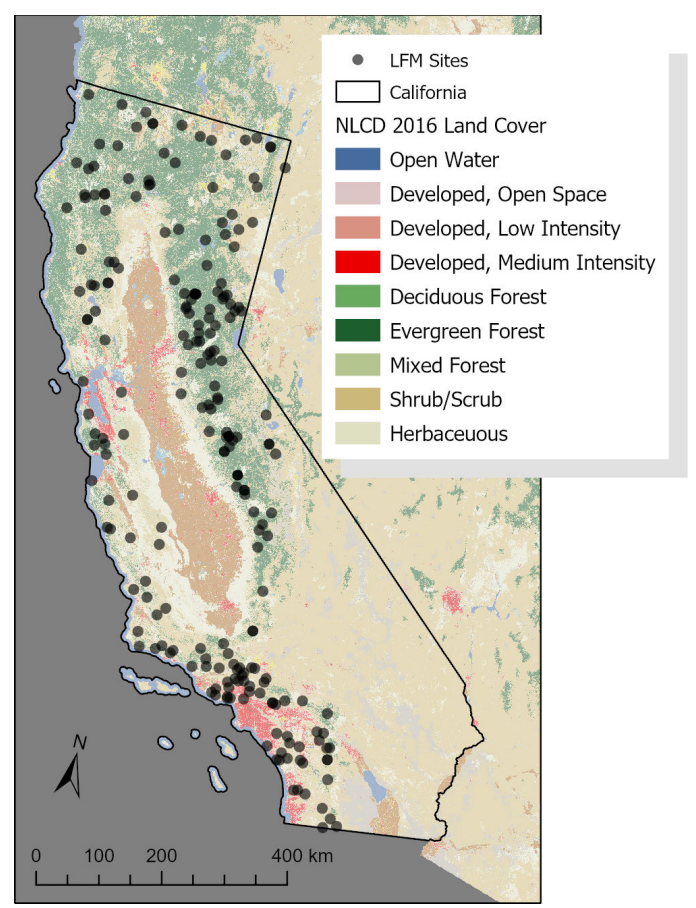

Figure 1. Active LFM sites in California. NLCD 2016 land cover at $30 \mathrm{~m}$ resolution is shown as the background.

In this study, we retrieved the SM time series from SMAP Enhanced L3 Radiometer Global Daily $9 \mathrm{~km}$ Soil Moisture product (SPL3SMP_E, version 3) using AppEEARS, a cloud-based data distributing service provided by NASA and USGS. Afternoon passes (6 PM local time) data were selected in favor of morning passes (6 AM local time) to avoid errors introduced by the excessive moisture in the surface soil before dawn. Afternoon passes also produce more reliable SM retrievals [11]. We used land cover data from the National Land Cover Database 2016 product at $30 \mathrm{~m}$ resolution [12] to support result interpretation.

We compared the LFM and SMAP SM time series at each site and the cross-site average of each date from Mar. 1, 2015 to Jan. 10, 2020. The top two land cover types, evergreen forest and shrub/scrub were picked to investigate the different lag relationship between the change of SM and LFM. Comparing these two primary land cover types in California's wilderness addressed the most typical fire-prone landscapes in California.

\section{RESULTS}

3.1. LFM measurements and SMAP SM across California Shrub/scrub contributed to the largest portion of the LFM measurements in California, with more than 4000 biweekly (or longer) measurements across 224 sites since April, 2015 (Fig. 2a).
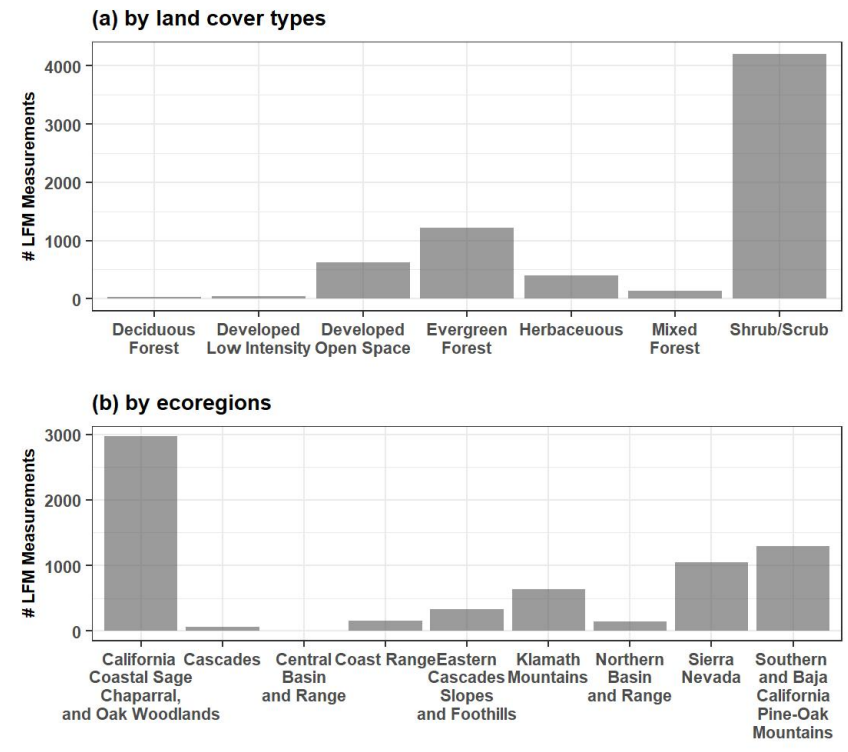

Figure 2. Number of LFM measurements between Mar. 1, 2015 and Jan. 10, 2020 in California by land cover types and EPA level III ecoregions.

These measurements were collected mostly in California's coastal sage and chaparral region as well as the Southern California mountains (Fig. 2b). LFM measurements for evergreen forest were largely collected in Sierra Nevada Mountains and Klamath Mountains located in Northern California, which possess a much more humid climate than the Mediterranean Southern California.

Evergreen forest and shrub/scrub is dominated in higher and lower latitudes of California, respectively, and showed differences in the dynamics of LFM and SM. Evergreen forest has a significantly higher level of LFM than shrub/scrub. However, the peak LFM of shrub/scrub could sometimes exceed the peak value of evergreen forest (Fig. 3a). LFM of evergreen forest also showed a smaller dynamic range than shrub/scrub. In contrary to LFM, SMAP SM showed a much greater value range in evergreen forest than shrub/scrub. The minimum SM was at a similar level during the driest months, despite land cover types. In other months, SM of evergreen forest exceeded shrub/scrub, with an exception in late December, 2019 (Fig. 3b).

LFM of shrub/scrub also spiked earlier than evergreen forest. Peaks of LFM occurred in mid spring for shrub/scrub sites but around mid-summer for evergreen forest. Such difference varied by years, depending on the moisture level. Similar with LFM, the occurrence of peak for SMAP SM also differed between these two land cover types. Shrub/scrub reached the peak SM earlier than evergreen forest. Yet the inter-annual variability of such difference was greater than LFM. In 2018, the driest year among the four years of study, evergreen forest peaked at the same time with shrub/scrub, an earlier occurrence than usual. 

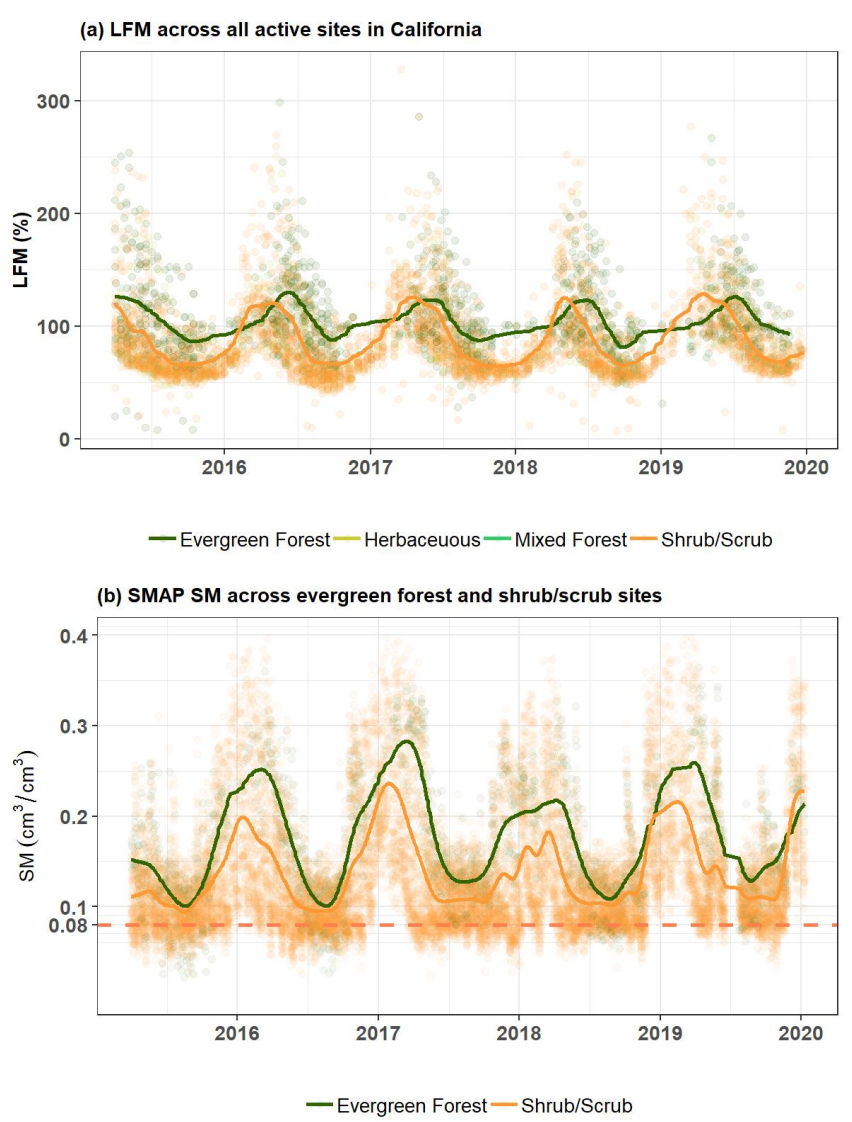

Figure 3. LFM (a) and SMAP SM (b) across active LFM sites in California. Smoothed LFM and SMAP SM are plotted as solid lines.

During the dry months when fire risk is high, SMAP SM was low and showed very limited variation, with most SM retrievals scattering around $0.08 \mathrm{~cm}^{3} / \mathrm{cm}^{3}$ (Fig. 3b), close to the background value (0.02) assigned to baseline SM retrieval algorithm. The limited dynamics resulted in "flat" time series during the driest months, which was more prominent in shrub/scrub than evergreen forest.

\subsection{Lagged relationship between SMAP SM and LFM}

LFM responses to the change in SM with a lag as it takes time for the associated plant physiological processes to reflect such change. A difference in the length of such lag was observed in our comparison between evergreen forest and shrub/scrub in California (Fig. 4). The average lag between SMAP SM and LFM from 2015 to 2019 in evergreen forest sites was 90 days, longer than the average 72 days lag in shrub/scrub sites during the same time (Table 1). The length of lag was relatively consistent across years for evergreen forest, despite the varying SM. In contrast, the shrub/scrub sites had a greater variability in terms of the length of lag between SMAP SM and LFM. The shortest lag was found in 2017-2018, when the SM was at the minimum among the four years of study. (a) Evergreen Forest

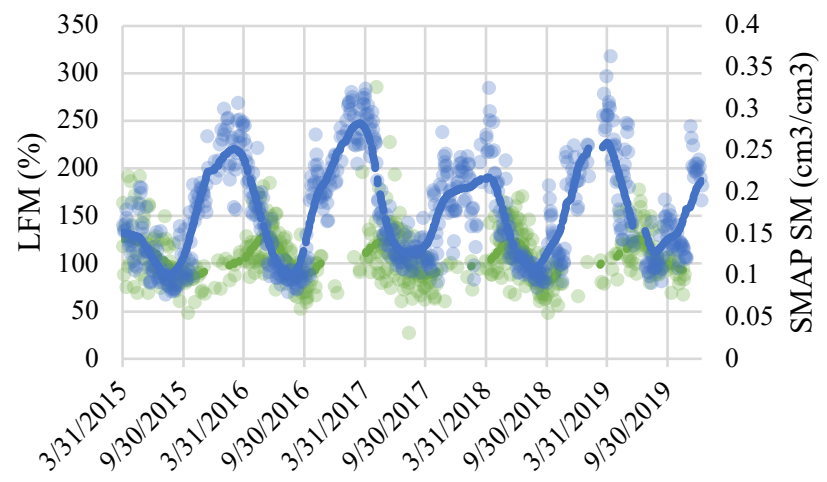

(b) Shrub/scrub

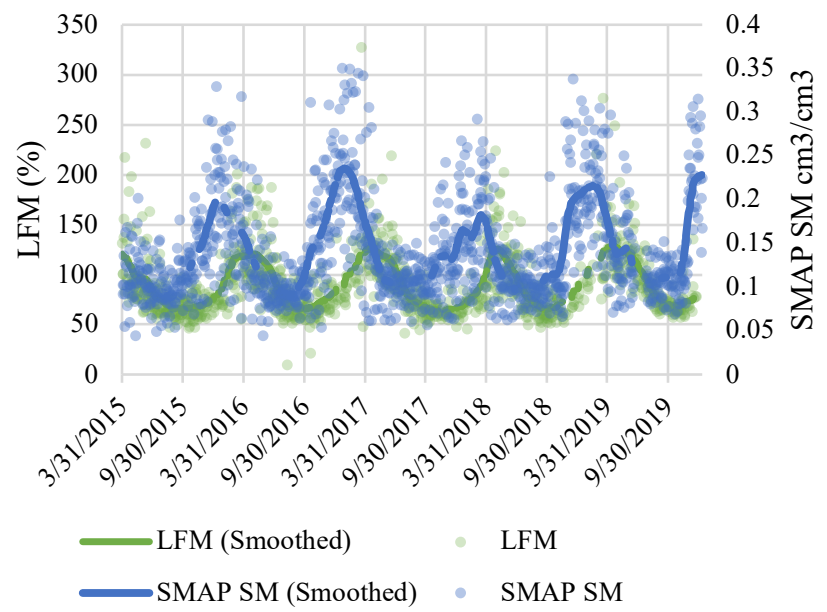

Figure 4. Time series of LFM and SMAP SM in evergreen forest (a) and shrub/scrub (b) of California. Note that time lags between LFM and SM.

Table 1. Average lag in days between SMAP SM and LFM across four water years in California from 2015 to 2019

\begin{tabular}{|c|c|c|c|c|c|}
\hline & $\begin{array}{c}2015- \\
2016\end{array}$ & $\begin{array}{c}2016- \\
2017\end{array}$ & $\begin{array}{c}2017- \\
2018\end{array}$ & $\begin{array}{c}2018- \\
2019\end{array}$ & Average \\
\hline $\begin{array}{c}\text { Evergreen } \\
\text { forest }\end{array}$ & 99 & 80 & 82 & 98 & 90 \\
\hline Shrub/scrub & 106 & 76 & 48 & 58 & 72 \\
\hline
\end{tabular}

\section{DISCUSSION}

Our results showed that LFM was able to maintain its characteristics despite the inter-annual variation of SM. For example, LFM in both land cover types showed a similar magnitude and pattern of dynamics between the driest year (2018) and other wetter years (Fig. 4). Furthermore, the higher SMAP SM level in evergreen forest did not translate to a greater LFM value. Despite the different peak time, LFM in evergreen forest was at the similar level as shrub/scrub (Fig. 3). Although the dynamics of SM determine the available moisture to support the physiological processes of plant, other factors related to the plant growing cycle should be introduced to achieve a better outlook estimate of the 
LFM. Moreover, the investigated region did not experience a severe drought during the period of study. Plants may be able to tolerate the current level of aridity and maintain the normal phenological cycle. The sensitivity of LFM towards SM needs further investigation with a longer time series of SM covering a greater range of moisture conditions, such as the prolonged drought in California from 2012 to 2015. Examining SM during post-fire vegetation recovery also will be required to understand lags between SM and LFM.

\section{CONCLUSIONS AND FUTURE PLAN}

This study addressed a much-needed investigation in the LFM dynamics across different land cover types at the regional level. We found that the majority of LFM measurements in California were taken in shrub/scrub and evergreen forest. California coastal sage, chaparral, and oak woodland was the ecoregion with highest number of LFM measurements. LFM in evergreen forest and shrub/scrub had a similar dynamic pattern and value range, despite a later peak time in evergreen forest. The inter-annual variability of LFM was small, in contrast to the great year-to-year variation of SM obtained from NASA SMAP. A lag of 2-3 months was found between SMAP SM and LFM in evergreen forest and shrub/scrub, with the former land cover type having a longer lag than the latter. The length of such lag was also relatively consistent across years, despite the different levels of aridity in soil. These findings indicated that other metrics are required to utilize the lagged relationship between SM and LFM for wildfire risk modeling.

While SMAP SM can be useful as presented in the paper, its coarse resolution limits the applicability to small areas and coastal region. In this regard, the NASA-ISRO SAR (NISAR) mission to be launched by mid 2022 will provide SAR data also at $\mathrm{L}$ band from which soil moisture can be derived at a much higher resolution (3-10 m). Moreover, SAR data at a higher frequency such as in $\mathrm{X}$ band or Ku band can be used to estimate soil moisture [13], especially over sparsely vegetated land such as in the fire-prone Southern California. Future X-band SAR mission such as LOTUSat-1 to be launched in 2023 with have an extensive lifetime overlapping with that of NISAR. Thus, the synergistic use of multifrequency data from NISAR and LOTUSat-1 will be advantageous to monitor soil moisture for wildfire danger outlooks.

\section{ACKNOWLEDGMENTS}

The research carried out at the Jet Propulsion Laboratory (JPL), California Institute of Technology, was supported by NASA Land Cover/Land Use Change Program and in part by the by the NASA Earth Science R\&A Program.

\section{REFERENCES}

[1] E. Chuvieco, J. Wagtendonk, D. Riaño, M. Yebra, and S. L. Ustin, "Estimation of Fuel Conditions for Fire Danger
Assessment," in Earth Observation of Wildland Fires in Mediterranean Ecosystems, E. Chuvieco Ed. Berlin, Heidelberg: Springer Berlin Heidelberg, 2009, pp. 83-96.

[2] P. E. Dennison and M. A. Moritz, "Critical live fuel moisture in chaparral ecosystems: a threshold for fire activity and its relationship to antecedent precipitation," Int $J$ Wildland Fire, vol. 18, no. 8, pp. 1021-1027, 2009. [Online]. Available: https://doi.org/10.1071/WF08055.

[3] S. H. Peterson, D. A. Roberts, and P. E. Dennison, "Mapping live fuel moisture with MODIS data: A multiple regression approach," (in English), Remote Sensing of Environment, vol. 112, no. 12, pp. 4272-4284, Dec 15 2008, doi: 10.1016/j.rse.2008.07.012.

[4] L. Wang, X. Quan, B. He, M. Yebra, M. Xing, and X. Liu, "Assessment of the Dual Polarimetric Sentinel-1A Data for Forest Fuel Moisture Content Estimation," Remote Sens-Basel, vol. 11, no. 13, p. 1568, 2019. [Online]. Available: https://www.mdpi.com/2072-4292/11/13/1568.

[5] L. Fan et al., "Evaluation of microwave remote sensing for monitoring live fuel moisture content in the Mediterranean region," Remote Sensing of Environment, vol. 205, pp. 210$223,2018$.

[6] S. Jia, S. H. Kim, S. V. Nghiem, and M. Kafatos, "Estimating Live Fuel Moisture Using SMAP L-Band Radiometer Soil Moisture for Southern California, USA," Remote Sensing, vol. 11, no. 13, p. 1575,2019 . [Online]. Available: https://www.mdpi.com/2072-4292/11/13/1575.

[7] M. Yebra, X. W. Quan, D. Riano, P. R. Larraondo, A. I. J. M. van Dijk, and G. J. Cary, "A fuel moisture content and flammability monitoring methodology for continental Australia based on optical remote sensing," (in English), Remote Sensing of Environment, vol. 212, pp. 260-272, Jun 2018, doi: 10.1016/j.rse.2018.04.053.

[8] M. Yebra, E. Chuvieco, and D. Riano, "Estimation of live fuel moisture content from MODIS images for fire risk assessment," (in English), Agr Forest Meteorol, vol. 148, no. 4, pp. 523-536, Apr 16 2008, doi: 10.1016/j.agrformet.2007.12.005.

[9] K. Rao, A. P. Williams, and A. G. Konings, "Remotely sensed live fuel moisture content across the Western USA and its relationship with climate aridity," in AGU Fall Meeting 2019, 2019: AGU.

[10] D. R. Weise, R. A. Hartford, and L. Mahaffey, "Assessing live fuel moisture for fire management applications," Assessing Live Fuel Moisture For Fire Management Applications. Pages 49-55 in Teresa L. Pruden and Leonard A. Brennan (eds.), 1998.

[11] S. K. Chan et al., "Development and assessment of the SMAP enhanced passive soil moisture product," (in English), Remote Sensing of Environment, vol. 204, pp. 931-941, Jan 2018. [Online]. Available: $<$ Go to ISI $>$ ://WOS:000418464400068.

[12] L. Yang et al., "A new generation of the United States National Land Cover Database: Requirements, research priorities, design, and implementation strategies," ISPRS Journal of Photogrammetry and Remote Sensing, vol. 146, pp. 108-123, 2018/12/01/ 2018, doi https://doi.org/10.1016/j.isprsiprs.2018.09.006.

[13] S. V. Nghiem et al., "Microwave Remote Sensing of Soil Moisture," Remote Sensing of Drought: Innovative Monitoring Approaches; Wardlow, BD, Anderson, MC, Verdin, JP, Eds, pp. 197-226, 2012. 